\title{
Real-Time Assay of the In- teraction of a GST Fusion Protein with a Protein Ligate Using Resonant Mirror Technique
}

BioTechniques 22:269-271 (February 1997)

Optical sensor techniques have recently been developed, which allow for the investigation of biomolecular interaction in real time. These techniques rely on the detection of changes in refractive index as ligate binds to a ligand, which is immobilized on a sensor surface. Examples of optical sensor techniques include surface plasmon resonance $(3,4)$ and the resonant mirror $(1,2)$.

The application of these systems for the investigation of protein - protein interactions necessitates the immobilization of one of the binding partners to the sensor surface. During this procedure, the binding activity of the protein should be retained. However, the latter could be reduced to a certain extent if the ligand is immobilized directly because immobilization can block the binding site or induce conformational changes of the protein. To overcome this problem, indirect immobilization strategies have been used, i.e., avidin covalently bound to the sensor matrix was used to capture biotin-labeled ligands (1).

Here we describe an efficient method for the investigation of a protein ligate binding to a recombinant glutathione S-transferase (GST) fusion protein using the resonant mirror technique. Since the direct immobilization of the GST-fusion protein phosphoinositide 3-kinase $\gamma$ (GST-PI3K $\gamma$ ) to a carboxymethyl dextran (CMD) matrix resulted in an almost complete loss of its binding activity to added ligate Ras, we developed a novel indirect immobilization procedure. We show that glutathione (GSH), only when immobilized by a 6-carbon spacer, captures GST-PI3K $\gamma$ efficiently and retains its binding activity. Under these conditions, specific binding of Ras to GSTPI3K $\gamma$ could be observed.

The study was performed on the interaction analysis system, IAsys ${ }^{\mathrm{TM}}$, 
from Affinity Sensors, Cambridge, England, UK (2). Recombinant PI3K $\gamma$ was expressed as a GST fusion protein in the baculovirus/Sf9 cell system and purified by GSH-Sepharose ${ }^{\circledR}$ affinity chromatography (6). The coupling kit and CMD cuvettes were supplied by Affinity Sensors (2) and GSH and 6aminohexanoic acid (6-AHA) by Sigma Chemical, Deisenhofen, Germany.

If not reported otherwise, all immobilizations were carried out following a standard carbodiimide immobilization protocol (2). GST-PI3K $\gamma$ was first immobilized directly in $100 \mu \mathrm{L} 10 \mathrm{mM}$ acetate buffer ( $\mathrm{pH} 4.5$ ) at a concentration of $100 \mu \mathrm{g} / \mathrm{mL}$. After subsequent addition of either GTP- or GDP-loaded Ras in binding buffer $(20 \mathrm{mM}$ phosphate, $2 \mathrm{mM} \mathrm{MgCl}_{2}, 0.1 \%$ Triton ${ }^{\circledR} \mathrm{X}$ 100 ), no significant binding signal could be observed.

In a second set of experiments, we tried to utilize the interaction of the GST tag with GSH for the indirect coupling of GST-PI3K $\gamma$ to the matrix. The immobilization of GSH to the CMD matrix was performed either directly or by the spacer 6-aminohexanoic acid (6AHA). A carboxymethyl dextran IAsys cuvette was equilibrated in phosphatebuffered saline (PBS) and 0.05\% Tween ${ }^{\circledR} 20$ and was then activated with a mixture of carbodiimide(EDC)/N-hydroxy succinimide (NHS) for $7 \mathrm{~min}$. After washing with PBS/Tween, GSH was immobilized at $100 \mu \mathrm{g} / \mathrm{mL}$ at $\mathrm{pH}$ 4.0 for $10 \mathrm{~min}$. Finally, the surface was blocked with $1 \mathrm{M}$ ethanolamine, $\mathrm{pH}$ 8.5 , for $2 \mathrm{~min}$ before re-equilibration in PBS/Tween.

To ensure efficient activation of the majority of the carboxyl groups within the carboxymethyl dextran IAsys cuvette, four successive activation cycles with EDC and NHS were performed. After washing with PBS/Tween, the 6AHA was immobilized at $10 \mathrm{mg} / \mathrm{mL}$ at pH 7.0 for 10 min. Following blocking with ethanolamine as above, the cuvette was activated two times more with EDC and NHS to activate the carboxyl groups introduced with the 6-AHA. After this activation stage, the GSH was immobilized at $10 \mathrm{mg} / \mathrm{mL}$ at $\mathrm{pH} 7.0$ followed by a final ethanolamine blocking.

Following binding of GSH, immobilization of GST-PI3K $\gamma$ was performed in $100 \mu \mathrm{L} \mathrm{PBS} /$ Tween at $0.5 \mu \mathrm{g} / \mu \mathrm{L}$
Table 1. Efficiency of Different Methods for Coupling GST-PI3K $\gamma$ to CMD Matrix and Subsequent Binding of the Ligate Ras

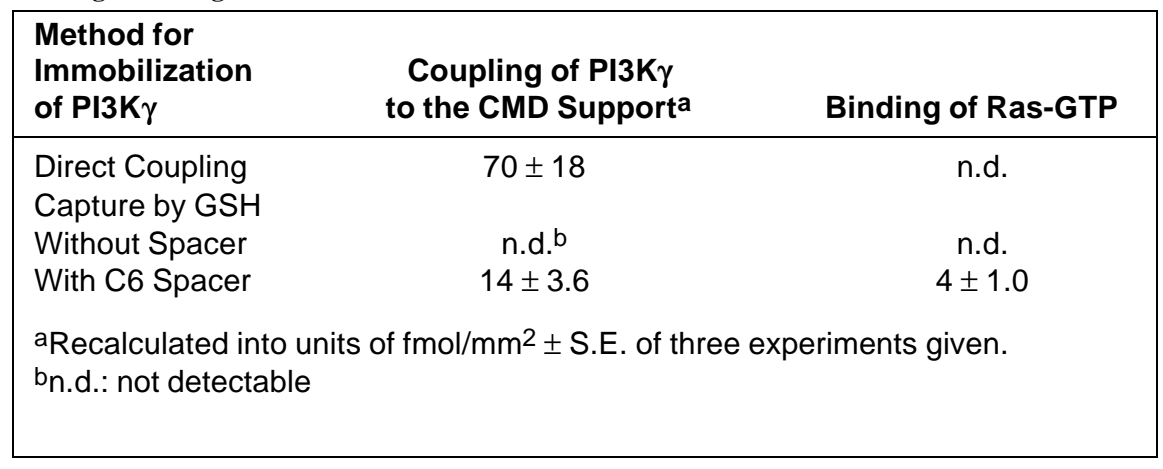

protein concentration. No detectable dissociation of bound PI3K $\gamma$ was observed after extensive washings with the same buffer containing $0.5 \mathrm{M} \mathrm{NaCl}$ or $1 \%$ Triton X-100. After immobilization of PI3K $\gamma$, the buffer was changed to $20 \mathrm{mM}$ phosphate, $2 \mathrm{mM} \mathrm{MgCl}$ and $0.1 \%$ Triton X-100. Wild-type H-Ras was pre-loaded with either GDP or GTP and added to the immobilized GST-PI3K $\gamma$ at a final concentration of 1 $\mu \mathrm{M}$. Real time assay of Ras binding was performed at $25^{\circ} \mathrm{C}$ according to the IAsys manufacturer's protocol.

While investigating protein ligands for human PI3K $\gamma(6)$, we recently discovered a GTP-dependent binding of the small GTPase Ras to the recombinant enzyme. To confirm these data by a direct binding assay, we used the resonant mirror technique. Several approaches for the coupling of GST$\mathrm{PI} 3 \mathrm{~K} \gamma$ to the CMD matrix were applied and then the ability of each particular surface for binding Ras was studied (Table 1). Additionally, the interaction of GST-PI3K $\gamma$ with GSH-coated cuvettes was investigated. With GSH immobilized directly, no binding to the CMD surface was observed. Using GSH immobilized by 6-AHA, it was possible to capture GST-PI3K $\gamma$ (Table 1).

A significant association of the ligate Ras to GST-PI3K $\gamma$ could only be observed when the ligand was captured by GSH immobilized by 6-AHA (Figure 1). The interaction of the enzyme with Ras depends strictly on the loading of the protein with GTP indicating

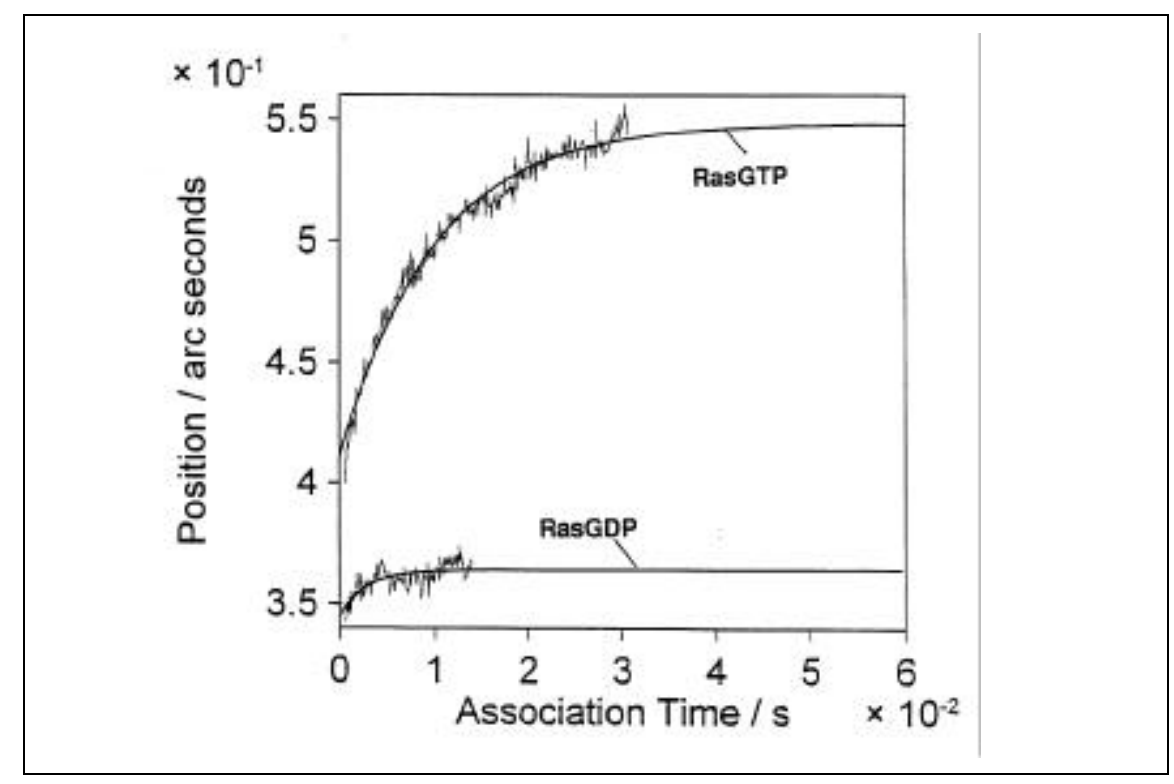

Figure 1. GTP-dependent binding of the ligate Ras to GST-PI3K $\gamma$ captured by immobilized GSH. Actual binding curves were fitted and extrapolated to the equilibrium extent by FASTfit software. 163 arc seconds correspond to $1 \mathrm{ng}$ protein $/ \mathrm{mm}^{2}$ sensor surface. 
the specificity of association (5). Determination of an association rate constant for the interaction of Ras-GTP and $\mathrm{PI} 3 \mathrm{~K} \gamma$ was beyond the scope of this study but seems possible by investigating ligate binding at different concentrations (3).

In summary, the resonant mirror technique offers a simple and efficient method for the direct real-time investigation of the association of GST-PI3K $\gamma$ with ligates, if the protein is bound indirectly by GSH to the matrix. We expect that this method could be exploited for the analysis of the interaction of other GST fusion proteins with their binding partners as well.

\section{REFERENCES}

1.Buckle, P., R.J. Davis, T. Kinning, D. Yeung, P.R. Edwards, D. Pollard-Knight and C.R. Lowe. 1993. The resonant mirror: a novel optical biosensor for direct sensing of biomolecular interactions part II: applications. Biosens.
Bioelectron. 8:355-363.

2.Cush, R., J.M. Cronin, W.J. Stewart, C.H. Maule, J. Molloy and N.J. Goddard. 1993.

The resonant mirror: a novel optical biosensor for direct sensing of biomolecular interactions part I: principle of operation and associated instrumentation. Biosens. Bioelectron. 8:347353.

3.End, P., I. Gout, M.J. Fry, G. Panayotou, R. Dhand, K. Yonezawa, M. Kasuga and M.D. Waterfield. 1993. A biosensor approach to probe the structure and function of the $\mathrm{p} 85 \mathrm{a}$ subunit of the phosphatidylinositol 3-kinase complex. J. Biol. Chem. 268:10066-10075.

4.Liedberg, B., C. Nylander and I. Lundstrum. 1983. Surface plasmon resonance for gas detection and biosensing. Sens. Actuators 4:299-304.

5.Rodriguez-Viciana, P., P.H. Warne, R. Dhand, B. Vanhaesebroeck, I. Gout, M.J. Fry, M.D. Waterfield and J. Downward. 1994. Phosphatidylinositol-3-OH kinase as a direct target of Ras. Nature 370:527-532.

6.Stoyanov, B., S. Volinia, T. Hanck, I. Rubio, M. Loubchenkov, D. Malek, S. Stoyanova, B. Vanhaesebroeck et al. 1995. Cloning and characterization of a human $\mathrm{G}$ protein-activated phosphoinositide 3-kinase. Science 692:690-693.
We thank Pablo Rodriguez-Viciana of London for providing purified Ras. This work was supported by Deutsche Forschungsgemeinschaft. Address correspondence to Reinhard Wetzker, Max Planck Research Unit "Molecular Cell Biology", Medical Faculty, University of Jena, Drackendorfer Strasse 1, 07747 Jena, Germany, Internet:i5rewe@rz.uni-jena.de

Received 19 March 1996; accepted 26 July 1996.

Ignacio Rubio, Philip Buckleㄹ, Hans Trutnau ${ }^{2}$ and Reinhard

Wetzker

University of Jena

Jena, Germany

${ }^{1}$ Affinity Sensors

Cambridge, England, UK

${ }^{2}$ Affinity Sensors, Fisons

Instruments Vertriebs GmbH

Mainz-Kastel, Germany 